University of Wollongong

Research Online

Faculty of Engineering and Information

Faculty of Engineering and Information

Sciences - Papers: Part A

Sciences

$1-1-2014$

A review of recent investigations on voltage unbalance management: Further contributions to improvement of IEC/TR 61000-3-13:2008

Jayatunga Vitharanage Upuli Priyadarshani Jayatunga

jvupj453@uowmail.edu.au

Sarath Perera

University of Wollongong, sarath@uow.edu.au

Philip Ciufo

University of Wollongong, ciufo@uow.edu.au

Ashish Agalgaonkar

University of Wollongong, ashish@uow.edu.au

Follow this and additional works at: https://ro.uow.edu.au/eispapers

Part of the Engineering Commons, and the Science and Technology Studies Commons

Research Online is the open access institutional repository for the University of Wollongong. For further information contact the UOW Library: research-pubs@uow.edu.au 


\title{
A review of recent investigations on voltage unbalance management: Further contributions to improvement of IEC/TR 61000-3-13:2008
}

\author{
Abstract \\ Voltage unbalance (VU) management in power systems essentially involves two major aspects: VU \\ emission allocation at the pre-connection stage and compliance assessment at the post-connection \\ stage of installations. This is a summary and a review paper on the recent investigations completed in \\ relation to VU emission assessment techniques which provide further contributions to the improvement \\ of IEC Technical Report IEC/TR61000-3-13:2008. Generalised approaches developed for the classification \\ of different sources of unbalance at the point of evaluation (covering both radial and interconnected \\ networks) and the evaluation of their individual contributions giving emphasis to the discrimination \\ between customer and network responsibility on VU emission are summarised. Some of the key aspects \\ used in the IEC VU emission allocation methodology which were reviewed using rigorous outcomes of the \\ proposed VU emission assessment techniques are presented in the paper.
}

\section{Keywords}

review, tr, recent, unbalance, management, further, contributions, improvement, voltage, iec, investigations, $2008,13,3,61000$

\section{Disciplines \\ Engineering | Science and Technology Studies}

\section{Publication Details}

U. Jayatunga, S. Perera, P. Ciufo \& A. P. Agalgaonkar, "A review of recent investigations on voltage unbalance management: Further contributions to improvement of IEC/TR 61000-3-13:2008," in 16th IEEE International Conference on Harmonics and Quality of Power (ICHQP), 2014, pp. 268-272. 


\title{
A Review of Recent Investigations on Voltage Unbalance Management: Further Contributions to Improvement of IEC/TR 61000-3-13:2008
}

\author{
U. Jayatunga, Sarath Perera, Phil Ciufo* and A. P. Agalgaonkar \\ School of Electrical, Computer and Telecommunications Engineering \\ University of Wollongong, Email: ciufo@uow.edu.au*
}

\begin{abstract}
Voltage unbalance (VU) management in power systems essentially involves two major aspects: VU emission allocation at the pre-connection stage and compliance assessment at the post-connection stage of installations. This is a summary and a review paper on the recent investigations completed in relation to $\mathrm{VU}$ emission assessment techniques which provide further contributions to the improvement of IEC Technical Report IEC/TR61000-3-13:2008. Generalised approaches developed for the classification of different sources of unbalance at the point of evaluation (covering both radial and interconnected networks) and the evaluation of their individual contributions giving emphasis to the discrimination between customer and network responsibility on VU emission are summarised. Some of the key aspects used in the IEC VU emission allocation methodology which were reviewed using rigorous outcomes of the proposed $\mathrm{VU}$ emission assessment techniques are presented in the paper.
\end{abstract}

Index Terms-power quality, voltage unbalance, voltage unbalance propagation, $\mathbf{k}_{\mathrm{uE}}$ factor, summation law, network asymmetry, load asymmetry

\section{INTRODUCTION}

$\mathbf{V}$ OLTAGE unbalance management requires the total VU absorption capacity of the power system to be distributed between all sources of unbalance including customer installations. Although, the connection of an unbalanced installation changes the existing unbalance level at the point of evaluation (POE), that installation is not solely responsible for the total change in $\mathrm{VU}$ at that location as network inherent asymmetries partly contribute to the same. In this regard, IEC Technical report IEC/TR 61000-3-13:2008 [1] provides guiding principles to system operators and owners in order to determine connection requirements of unbalanced installations prescribing individual VU emission limits.

Recent work presented in [2] make further contributions to the process of $\mathrm{VU}$ management with new $\mathrm{VU}$ emission assessment techniques by extending preliminary work on the CIGRE/CIRED C4.109 joint working group report on emission assessment techniques [3] to ensure that the imposed emission allocations are met. Identification of sources of unbalance and quantification of their individual contributions [4] at the POE are important while understanding the complex interactions which take place between the different sources of unbalance [5]. Further, it is vital to be able to determine principal emission contributors in a given power network

NOTICE: this is the authors' version of a work that was accepted for publication in the ICHQP proceedings. Changes resulting from the publishing process, such as peer review, editing, corrections, structural formatting, and other quality control mechanisms may not be reflected in this document Changes may have been made to this work since it was submitted for publication. A definitive version was subsequently published in the Proceedings of the 16th IEEE International Conference on Harmonics and Quality of Power, May 2014, DOI:10.1109/ICHQP.2014.6842912 since such methodologies will facilitate the implementation of mitigation measures to reduce network VU [6]. Such techniques should ensure that the VU emission contributions made by different sources of unbalance are determined using data which are not overly demanding, especially from a utility perspective. VU propagation in networks is also an aspect which needs consideration in order to evaluate the influence made by background unbalance sources in the emission assessment process [7]. Sections II, III, IV and V of this paper summarise the significant outcomes of recent investigations on VU emission assessment, quantification of VU propagation coefficients, revised $\mathrm{k}_{\mathrm{uE}}$ factor approach for sharing unbalance between load and line asymmetries and development of a statistical approach for VU summation respectively.

\section{POST-CONNECTION VU EMISSION ASSESSMENT IN} RADIAL AND INTERCONNECTED NETWORKS [4], [5]

Deterministic methodologies given in [4] and [5] present generalised approaches for identifying different sources of unbalance at the POE while separating the customer and network responsibility on VU emission. Accordingly, the resultant post-connection $\mathrm{VU}$ emission measurement at the POE was decomposed into three factors by identifying major VU emission contributors as follows:

- load asymmetry (local load connected at the POE)

- line asymmetries (untransposed line(s) connected to the busbar under assessment i.e. POE)

- background unbalance (upstream or surrounding busbars that are connected to the busbar under assessment, represented using unbalanced voltage sources)

Hence, the constituent components of the resultant postconnection VU emission at the POE can be established as asymmetrical load contribution, asymmetrical line contribution and upstream/surrounding source contribution which are given in (1) in terms of the complex VU factors ${ }^{1}$ for radial networks and in (2) for interconnected networks.

$$
V U F_{P O E}=V U F_{P O E}^{\text {load }}+V U F_{P O E}^{\text {line }}+V U F_{P O E}^{\text {source }}
$$

where, $V U F_{P O E}$ is the resultant (total) VUF at the POE; $V U F_{P O E}^{\text {load }}$ is the $\mathrm{VU}$ emission contribution made by load asymmetry; $V U F_{P O E}^{\text {line }}$ is the VU emission contribution made by line asymmetry and $V U F_{P O E}^{\text {source }}$ is the VU emission contribution made by upstream source.

$$
V U F_{k}=V U F_{k}^{\text {load }}+V U F_{k}^{\text {line }}+V U F_{k}^{\text {d_source }}
$$

where, $V U F_{k}$ is the resultant VUF at busbar k (i.e. busbar under assessment); $V U F_{k}^{\text {load }}$ is the VU emission contribution

${ }^{1} \mathrm{VU}$ factor (VUF) is defined as the ratio of negative sequence voltage to positive sequence voltage. 
TABLE I

VU EMISSION ASSESSMENT OUTCOMES: RADIAL NETWORKS

\begin{tabular}{|l|l|}
\hline Individual contributor & Mathematical expression for the contribution made \\
\hline Passive loads & $\left(V U F_{P O E}-C U F\right) \frac{V_{\text {reg-line }}}{\left(1+V_{\text {reg-line }}\right)}$ \\
\hline Load asymmetry $V U F_{P O E}^{\text {load }}$ & $-\frac{Z_{21, t}}{Z_{11, t}} \frac{V_{\text {reg-line }}\left(1+V_{\text {reg-line }}\right)}{|l|}$ \\
\hline Line asymmetry $V U F_{P O E}^{\text {line }}$ & $V U F_{\text {source }}$ \\
\hline Source asymmetry $V U F_{P O E}^{\text {source }}$ & $-\left(\frac{Z_{2, m}}{Z_{1, m}}\right)\left(\frac{Z_{21, t}}{Z_{22, t}+Z_{2, m}}\right)$ \\
\hline Induction motor loads & $\left(\frac{Z_{2, m}}{Z_{1, m}}\right)\left(\frac{Z_{1, m}+Z_{11, t}}{Z_{2, m}+Z_{22, t}}\right) V U F_{\text {source }}$ \\
\hline Line asymmetry $V U F_{P O E}^{\text {line }}$ & $\left(V U F_{P O E}-C U F_{\mathrm{Pload}}\right)\left(\frac{Z_{1, m} Z_{2, m}\left(1+V_{\text {reg-line }}\right)+Z_{22, t}\left(Z_{1, m}-Z_{2, m}\right)}{Z_{2, m}}\right)$ \\
\hline Source asymmetry $V U F_{P O E}^{\text {source }}$ & $-\frac{Z_{21, t}}{Z_{11, t}}\left(\frac{Z_{1, m} Z_{2, m} V_{\text {reg-line }}}{Z_{1, m} Z_{2, m}\left(1+V_{\text {reg-line }}\right)+Z_{22, t}\left(Z_{1, m}-Z_{2, m}\right)}\right)$ \\
\hline Mixed loads & $\left(\frac{Z_{1, m} Z_{2, m}\left(1+V_{\text {reg-line }}\right)}{Z_{1, m} Z_{2, m}\left(1+V_{\text {reg-line }}\right)+Z_{22, t}\left(Z_{1, m}-Z_{2, m}\right)}\right) V U F_{\text {source }}$ \\
\hline Load asymmetry $V U F_{P O E}^{\text {load }}$
\end{tabular}

TABLE II

VU EMISSION ASSESSMENT OUTCOMES: INTERCONNECTED NETWORKS

\begin{tabular}{|l|l|}
\hline Individual contributor & Mathematical expression for the contribution made \\
\hline Passive loads & $\sum_{i \neq k}^{n}\left(C U F_{k}-V U F_{k}\right) \frac{Y_{11: k i}}{Y_{22: k k}} V_{\text {drop-t }(k-i)}$ \\
\hline Load asymmetry $V U F_{k}^{\text {load }}$ & $-\sum_{i \neq k}^{n} \frac{Y_{21: k i}}{Y_{22: k k}} V_{\text {drop-t }(k-i)}$ \\
\hline Line asymmetry $V U F_{k}^{\text {line }}$ & $-\sum_{i \neq k}^{n} \frac{Y_{22: k i}}{Y_{22: k k}}\left(1+V_{\text {drop-t }(k-i)}\right) V U F_{i}$ \\
\hline Source asymmetry $V U F_{k}^{\text {d_source }}$ & $\sum_{i \neq k}^{n} \frac{Y_{21: k i} V_{\text {drop-t }(k-i)}}{Y_{2: m}-Y_{22: k k}}$ \\
\hline Induction motor loads & $\sum_{i \neq k}^{n} \frac{Y_{22: k i}\left(1+V_{\text {drop-t(k-i) }}\right)}{Y_{2: m}-Y_{22: k k}} V U F_{i}$ \\
\hline Line asymmetry $V U F_{k}^{\text {line }}$ \\
\hline Source asymmetry $V U F_{k}^{\text {d_source }}$ \\
\hline
\end{tabular}

made by the $k^{\text {th }}$ bus load at busbar $\mathrm{k} ; V U F_{k}^{\text {line }}$ is the VU emission contribution made by all lines connected to busbar $\mathrm{k}$ which can be expanded as $\sum_{i \neq k}^{n} V U F_{k-i}^{\text {line }}\left(V U F_{k-i}^{\text {line }}\right.$ is the contribution made by the line $k-i$ (line between busbars $k$ and $i$ ) on busbar k); $V U F_{k}^{\mathrm{d}}$ ssource is the VU emission contribution made by surrounding (local) busbars which are connected to busbar $k$ via lines $\left(\sum_{i \neq k}^{n} V U F_{k=i}^{\mathrm{d} \_ \text {source }}\right)$.

Mathematical formulations presented in [4] and [5] evaluate the three components as decoupled VU contributions in such a way that they reflect the individual asymmetries through the decoupled formulation. These individual contributions are given in Tables I and II for radial and interconnected networks respectively for different load types considered. Referring to Table I;

$C U F_{\text {Pload }}$ is the current unbalance factor of the passive load, $V U F_{\text {source }}$ is the VUF of the upstream busbar, $Z_{x y, t}$ is the sequence impedance of the transmission line. $x$ and $y$ can be replaced with 1 and 2 which stand for positive and negative sequence respectively, $V_{\text {reg-line }}$ is the voltage regulation of the line defined as the ratio of positive sequence voltage drop in the line to positive sequence voltage at the load end, $Z_{x, \mathrm{~m}}$ is the sequence impedance of the motor $(x=1$ or 2$)$.

Referring to Table II;

$C U F_{k}$ is the current unbalance factor at $k^{t h}$ busbar, $V U F_{k}$ is the VUF at $k^{t h}$ busbar, $Y_{x y: k i}$ refers to elements of nodal bus admittance matrix developed for the network in the sequence domain. $x$ and $y$ can be replaced with 1 and 2 which stand for positive and negative sequence respectively. $k$ and $i$ represent different busbars, $V_{\text {drop-t }(k-i)}$ is the normalised voltage drop of line $k-i$ (normalised using bus $k$ voltage) defined as
$\frac{U_{1, i}-U_{1, k}}{U_{1, k}}$ where $U_{1, x}$ is the positive sequence voltage of busbar $x$. In the analysis of the radial power system (in Table I), this voltage drop was identified as voltage regulation because of the unidirectional power flow from source to load.

\section{VU PROPAGATION [7]}

VU emission allocation methodology [1] incorporates the effects of VU propagation in evaluating individual emission limits by introducing two quantitative measures. In a radial network, the level of VU that is transfered to the downstream busbar from upstream is expressed as a portion of the planning level of the upstream busbar which is scaled down using a transfer coefficient. An influence coefficient is used to address the influences made by neighbouring busbars at the POE in interconnected networks. The work covered in [2], [7] presents novel deterministic approaches to quantify coefficients associated with VU propagation based on the VU emission assessment outcomes given in [4] and [5]. The level of background unbalance that is transfered to the POE is separated by establishing the contribution made by upstream/surrounding busbars which is expressed as a portion of upstream/surrounding busbar VU factors. Thus, VU propagation coefficients can be evaluated using the scaling factor associated with source contributions (i.e. in radial networks, $p c_{p o e-u s}^{x}=\frac{V U F_{P O E}^{\text {source }}}{V U F_{\text {source }}}$ and in interconnected networks, $\left.p c_{k-i}^{x}=\frac{V U F_{k-i}^{\mathrm{d}_{-} \text {source }}}{V U F_{i}}\right)$ and are specified in terms of known system parameters for different load types as given in Table III. $P C_{\text {poe-us }}^{x}=\left|p c_{p o e-u s}^{x}\right|$ is the VU propagation coefficient associated with downstream busbar (POE) which contains a ' $x$ ' type (passive, induction motor 
TABLE III

VU PROPAGATION COEFFICIENTS AT THE BUSBAR UNDER ASSESSMENT

\begin{tabular}{|l|l|l|l|}
\hline Type of load at POE & Radial network & \multicolumn{2}{|l|}{ Interconnected network } \\
\hline Passive loads & $P C_{p o e-u s}^{p l}=1$ & $P C_{k-i}^{p l}=\frac{Y_{22: k i}}{Y_{22: k k}}\left(1+V_{\text {drop-t }(k-i)}\right)$ \\
\hline Induction motor loads & $P C_{p o e-u s}^{\text {im }}=\left|\left(\frac{Z_{2, m}}{Z_{1, m}}\right)\left(\frac{Z_{1, m}+Z_{11, t}}{Z_{2, m}+Z_{22, t}}\right)\right|$ & $P C_{k-i}^{i m}=\frac{Y_{22: k i}\left(1+V_{\mathrm{drop}-\mathrm{t}(k-i)}\right)}{Y_{2: m}-Y_{22: k k}}$ \\
\hline Mixed load & $P C_{p o e-u s}^{m l}=\mid\left(\frac{Z_{1, m} Z_{2, m}\left(1+V_{\text {reg-line }}\right)}{Z_{1, m} Z_{2, m}\left(1+V_{\text {reg-line }}\right)+Z_{22, t}\left(Z_{1, m}-Z_{2, m}\right)}\right)$ & & \\
\hline
\end{tabular}

or mixed) load and $P C_{k-i}^{x}=\left|p c_{k-i}^{x}\right|$ is the VU propagation coefficient associated with busbar $\mathrm{k}$ (which contains a ' $x$ ' type (passive, induction motor) load) resulting from the influence made by busbar ' $i$ '.

For a mixed load, the $P C_{\text {poe-us }}^{m l}$ is used to compare the IEC approach which determines the MV to LV transfer coefficients using $T_{\mathrm{uML}}={\frac{1}{1+k_{m} \frac{k_{s}-1}{k}}}^{2}$. The following scenario demonstrates the variation of VU propagation coefficient over different load compositions of a 1.2 MVA mixed load in a radial network $(2.3 \mathrm{kV}, 500 \mathrm{hp}$ three-phase induction motor loads and $2.3 \mathrm{kV}$ constant power load) using two approaches. As shown in Fig. 1, when the load comprises only passive loads (i.e. $k_{m}=0$ ), the VU propagation coefficient is equal to unity as expected. That is, the total upstream VU emission is transfered to the POE with no attenuation. When the proportion of the motor load is increased in the mixed load, the transfer coefficient decreases as a result of the increased VU attenuation provided by induction motors. The maximum attenuation can be obtained when $k_{m}=1$ (i.e. total load is composed of three-phase induction motors only). Further, it can be seen that the outcomes of the IEC approach for evaluating VU transfer coefficients is slightly conservative compared to the proposed approach when the mixed load has a higher proportion of induction motor loads. The VU

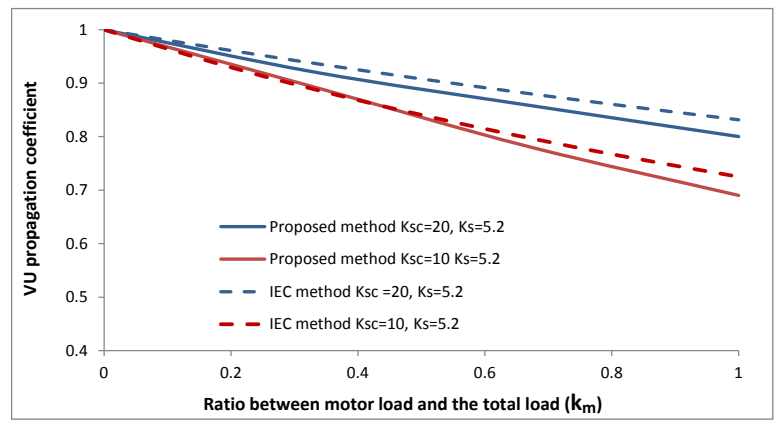

Fig. 1. VU propagation coefficients evaluated for a radial network in the presence of a mixed load in comparison to the IEC approach

propagation coefficients evaluated for the IEEE 14 bus test system [2] which contains voltage controlled busbars where negligible VU emission levels are assumed at busbars 1, 2, 3, 6 and 8 are shown in Table IV. Further, 14 bus test system is assumed to supply three-phase balanced constant power loads since the propagation coefficients have been noted to be independent of both load and network asymmetries. The deterministic methodologies developed for radial networks provide a sound basis for the determination of MV-LV VU

${ }^{2} k_{m}$ is the ratio of rated motor power in MVA to total MVA load supplied by the LV system; $k_{s}$ is the ratio between positive and negative sequence impedances of the motor load supplied by the LV system; $k_{s c}$ is the ratio of LV short circuit level to total load in MVA supplied by the LV system.
TABLE IV

VU PROPAGATION COEFFICIENTS - IEEE 14 BUS TEST SYSTEM

\begin{tabular}{|l|l|l|l|}
\hline Busbar under & \multirow{2}{*}{$\begin{array}{l}\text { Local } \\
\text { assessment }\end{array}$} & \multirow{2}{*}{$\begin{array}{l}i \\
\text { busbar }\end{array}$} & \multicolumn{2}{|l|}{ VU Prop. coefficient $p c_{k-i}^{p l}$} \\
\cline { 3 - 4 } & & $\begin{array}{l}\text { Magnitude } \\
P C_{k-i}^{p l}\end{array}$ & $\begin{array}{l}\text { angle (in de- } \\
\text { grees) }\end{array}$ \\
\hline 4 & 5 & 0.57 & 0.07 \\
\hline 4 & 7 & 0.13 & -0.30 \\
\hline 4 & 9 & 0.05 & -0.34 \\
\hline 5 & 4 & 0.62 & 0.0 \\
\hline 9 & 4 & 0.07 & -0.06 \\
\hline 9 & 7 & 0.37 & -0.12 \\
\hline 9 & 10 & 0.45 & 0.10 \\
\hline 9 & 14 & 0.13 & 0.09 \\
\hline 10 & 9 & 0.70 & 0.0 \\
\hline 10 & 11 & 0.31 & 0.0 \\
\hline 11 & 10 & 0.51 & 0.0 \\
\hline 12 & 13 & 0.49 & 0.0 \\
\hline 13 & 12 & 0.03 & 0.0 \\
\hline 13 & 14 & 0.91 & 0.0 \\
\hline 14 & 9 & 0.03 & 0.0 \\
\hline 14 & 13 & 0.97 & 0.0 \\
\hline
\end{tabular}

transfer coefficient whereas new VU propagation coefficients for interconnected networks can be used to evaluate the influence coefficients in HV and EHV networks. Further, consideration of a scalar quantity for the VU propagation coefficient is sufficient as the phase angles associated with $p c_{k-i}^{x}$ are nearly zero. In the case of passive loads connected at the POE, VU propagation coefficient is equal to unity in radial networks whereas it primarily depends on the network topology in interconnected networks. $P C_{\text {poe-us }}^{i m}$ or $P C_{k-i}^{i m}$ evaluated at busbars with induction motor loads are always less than unity since three-phase induction motors tend to attenuate pre-existing VU levels at the connected busbar regardless of the network characteristics.

\section{IV. $\mathrm{K}_{\mathrm{uE}}$ FACTOR [8]}

As per [1], the $\mathrm{k}_{\mathrm{uE}}$ factor accounts for the unbalance emission that arises due to the load asymmetry whereas $\mathrm{k}_{\mathrm{uE}}^{\prime}\left(1-\mathrm{k}_{\mathrm{uE}}\right)$ accounts for unbalance that arises due to the network asymmetry. The recent investigations on VU emission assessment led to the derivation of the $\mathrm{k}_{\mathrm{uE}}$ factor as a vector quantity by simplifying (1) under balanced upstream source conditions (i.e. $V U F_{P O E}=V U F_{P O E}^{\text {load }}+V U F_{P O E}^{\text {line }}$ ). Thus, in the case of passive or mixed loads at the POE, the $\mathrm{k}_{\mathrm{uE}}$ factor is evaluated using (3) which illustrates its sensitivity to the level of current unbalance of the passive load and network asymmetry.

$$
\mathrm{k}_{\mathrm{uE}}=\frac{C U F}{C U F+\frac{Z_{21, t}}{Z_{11, t}}}
$$

Naturally, three-phase induction motors do not possess any inherent unbalance other than the fact that their operation is affected by the external supply source VU [4]. No term exists corresponding to load asymmetry ( $\left.V U F_{\mathrm{POE}}^{\text {load }}\right)$ in the 
methodology for induction motors as a consequence of the symmetrical nature of the three-phase induction motor. Thus, (3) or the existing ' $\mathrm{k}_{\mathrm{uE}}$ factor' approach does not lead to a meaningful VU emission allocation for induction motor loads although the IEC methodology does not make any dispensation to customer allocations which contain induction motor loads. In contrary to the $\mathrm{k}_{\mathrm{uE}}$ factor approach, a new concept can be developed to quantify the VU emission attenuation provided by an induction motor which helps improve the total emission allocation capacity of the particular power system. Such a quantity can be used to enhance the limit of unbalance absorption capacity prior to apportioning VU emission between load and network asymmetries.

A comparison of $\mathrm{k}_{\mathrm{uE}}$ factors for a radial network with passive loads ${ }^{3}$ using different methods is given in Fig. 2.

$$
\begin{aligned}
\left|\mathrm{k}_{\mathrm{uE}}\right| & =\left|\frac{C U F}{C U F+\frac{Z_{21, t}}{Z_{11, t}}}\right| \\
\mathrm{k}_{\mathrm{uE}} & =\left(\left|\frac{U_{\text {loads }}}{U_{\text {global }}}\right|\right)^{\alpha} \\
\mathrm{k}_{\mathrm{uE}} & =\frac{\left|C_{i}\right|^{\alpha}}{\left|C_{i}\right|^{\alpha}+\left(\left|\frac{Z_{12}}{Z_{11}}\right|\right)^{\alpha}}
\end{aligned}
$$
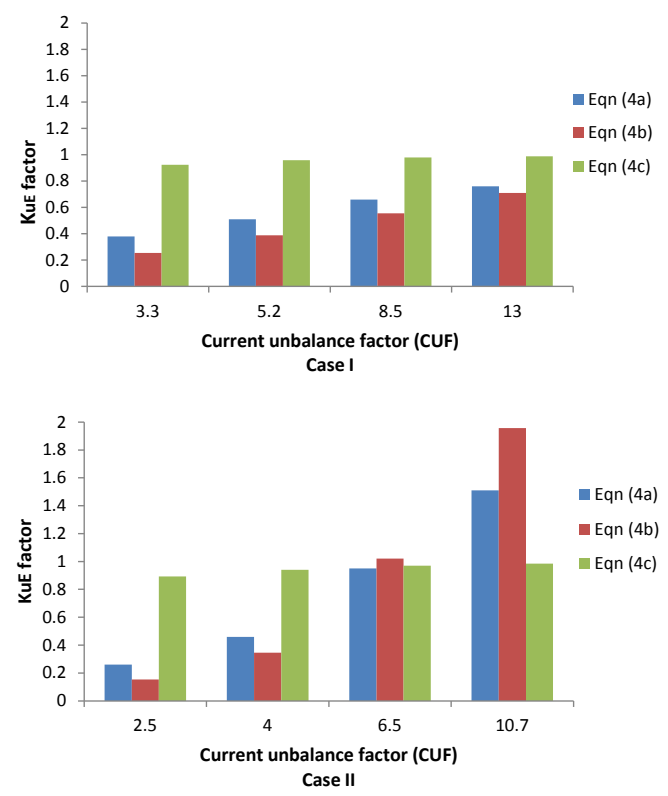

Fig. 2. Comparison of $\mathrm{k}_{\mathrm{uE}}$ factors evaluated for a radial network supplying a constant power load

It is to be noted that (4a) derives $\mathrm{k}_{\mathrm{uE}}$ as a vector quantity, whereas (4b) and (4c) give only absolute values. $\mathrm{k}_{\mathrm{uE}}$ values that are obtained using $(4 \mathrm{c})$ are seen to be almost constant for a specific case irrespective of the load unbalance level (i.e. current unbalance factor). In addition, they do not show any significant variation even between Cases I and II due to the fact that $\frac{Z_{12}}{Z_{11}}$ is constant for a given network and the CUF has a limited variation as utilities attempt to control load unbalance in the range $10 \%-15 \%$. Further, the same CUF (magnitude) can arise due to different unbalanced load

${ }^{3} 10$ MVA single phase constant power loads having different power factors $(0.85,0.55,0.9$ in $\mathrm{A}, \mathrm{B}, \mathrm{C}$ phases respectively). In Case I load configuration, different CUFs were obtained by changing phase B power factor. In Case II, loads in phase $\mathrm{B}$ and $\mathrm{C}$ were swapped [8]. configurations, thus, the evaluation of $\mathrm{k}_{\mathrm{uE}}$ using (4c) does not distinguish such situations. Eqn. (4b), which is derived based on the IEC definition, takes the impact of the phasor aspect of unbalance into account using the summation law. Referring to Fig. 2, with respect to Case I, results obtained from (4a) and (4b) have some agreement whereas discrepancies arise in Case II for some current unbalance levels.

Similar to the $\mathrm{k}_{\mathrm{uE}}$ factor approach, $\mathrm{k}_{\mathrm{uE}}^{\prime}$ can be determined for different types of loads as follows: For passive loads and mixed loads ${ }^{4}$ connected at the POE (in a radial network);

$$
\mathrm{k}_{\mathrm{uE}}^{\prime}=\frac{\frac{Z_{21, t}}{Z_{11, t}}}{C U F+\frac{Z_{21, t}}{Z_{11, t}}}
$$

For three-phase induction motor loads connected at the POE (in a radial network), $\mathrm{k}_{\mathrm{uE}}^{\prime}$ takes the value of unity under balanced upstream source conditions. That is, total unbalance is equal to the contribution made by network asymmetry as there is no VU propagated from upstream. However, this situation changes when the upstream unbalance is taken into account as the total VU emission at the POE comprises the propagated portion of upstream unbalance in addition to the contribution made by network asymmetry. These findings reveal that the factor $\mathrm{k}_{\mathrm{uE}}^{\prime}$ is also dependent on various system parameters including the type of load connected at the POE, phasor orientation of load and line emission vectors, and the level of load unbalance.

\section{REVised General Summation LAW FOR VU [2]}

As per the IEC Technical Report [1], the resultant VU emission at a POE is the vector summation of negative sequence voltage components which arise as a result of the interactions of various sources of unbalance. The dynamic nature of the power system causes VU to randomly vary in time. Thus, representation of all scattered emission vectors in time as stochastic quantities using a general summation law $\left(u=\sqrt[\alpha]{\sum\left(u_{i}\right)^{\alpha}} ; u\right.$ - magnitude of the resulting VUF of aggregated unbalance sources (probabilistic value); $u_{i}$ magnitude of an individual VU emission level to be combined; $\alpha$-summation law exponent.) avoids the need for phase angle information. The IEC/TR 61000-3-13:2008 gives an indicative value of $\alpha=1.4$ considering a $95 \%$ non-exceeding probability level and based on the fact that the operation of most unbalanced installations are unlikely to produce simultaneous or in-phase emissions in practice.

Based on the analysis of VU emission assessment outcomes adopting the present statistical approach ${ }^{5}$, some observations can be made to identify the conditions to be satisfied in order to use the present general summation law for the aggregation of scattered unbalance levels which are generated by randomly changing loads. Accordingly, if two groups of randomly scattered VU sources are considered, the application of a general summation law is applicable where:

- the contribution made by one set of emission vectors is comparatively insignificant compared to the influential contributor and/or

- all emission phasors are scattered in a small segment leading to an increase of the resultant emission level compared to the most influential contributors (i.e. when

${ }^{4}$ Considering the approximations used in deriving $\mathrm{k}_{\mathrm{uE}}$

${ }^{5}$ By modifying complex VUF based formulation [4] to incorporate the application of the general summation law in relation to the determination of individual emission contributions 
fictitious single emission phasors are derived to replace all individual emission phasors in a group, the phase angle between those two fictitious phasors should be smaller than 90 degrees)

The above conditions are reviewed in [2] by considering the deterministic formulation on VU emission assessment [4]. Based on the observation that the randomly scattered VU emission phasors do not distribute over the entire 360 degree plane at all times, clustered emission phasors lead to a statistically significant dominant emission contribution influencing the resultant VU emission at the POE. Therefore, the existing summation law is revised by introducing a new coefficient to signify the contribution made by individual VU sources on the resultant VU emission depending on the network specifications as shown in (6).

$$
V U F_{P O E, \text { stat }}=\sqrt[\alpha]{\sum K_{i}\left(V U F_{i}\right)^{\alpha}}
$$

where $\alpha=1.4$ and $K_{i}$ is a coefficient which functions as a weighting factor on the influence made by each contributor depending on its magnitude and phasor orientation. When the VU emission contributors $\left(V U F_{P O E}^{\text {load }}\right.$ and $\left.V U F_{P O E}^{\text {line }}\right)$ are considered in relation to the $\mathrm{VU}$ emission assessment in radial networks with passive loads connected at the POE, the coefficient $K_{i}$ can be established considering facts that the summation of the scattered VU emission phasors is influenced by the relative phasor orientation of both contributors $\left(V U F_{P O E}^{\text {load }}\right.$ and $\left.V U F_{P O E}^{\text {line }}\right)$ which is approximately given by the phasor angle between $C U F$ and $\frac{Z_{21, t}}{Z_{11, t}}$ and the significance of both contributors which can be evaluated using the ratio of magnitudes of individual contributions.

In the selection criteria for weighing coefficients $\left(K_{i}\right)$, the following notations are used in relation to the individual emission contributions made by load and line asymmetries of a given radial network configuration.

- $A$ - Most significant contributor making an emission contribution of " $a$ " (magnitude)

- $B$ - Least significant contributor making an emission contribution of " $b$ " (magnitude).

Thus, the ratio of least significant emission contribution to most significant emission contribution is given by $\frac{b}{a}$. The coefficients $K_{i}$ can be selected from Table V based on the phase angle between two emission contributors (phase angle between $C U F$ and $\frac{Z_{21, t}}{Z_{11, t}}$ ) and the ratio of $\frac{b}{a}$ which governs the influence of each emission contributor.

TABLE V

$K_{i}$ COEFFICIENTS - RADIAL NETWORK WITH PASSIVE LOADS

\begin{tabular}{|l|l|l|l|}
\hline Emission & \multicolumn{3}{|l|}{$K_{i}$ coefficient } \\
\cline { 2 - 4 } & $\begin{array}{l}\text { Phase angle be- } \\
\text { tween } C U F \text { and }\end{array}$ & $\begin{array}{l}\text { Phase angle between } C U F^{\prime} \text { and } \\
Z_{21, t}\end{array} Z_{11, t}>90 \mathrm{deg}$ \\
\cline { 2 - 4 } & $\frac{Z_{21, t}}{Z_{11, t}}<90 \mathrm{deg}$ & Ratio $\left(\frac{b}{a}\right) \leq 0.5$ & $\operatorname{Ratio}\left(\frac{b}{a}\right)>0.5$ \\
\hline $\mathrm{A}$ & 1 & 1 & -1 \\
\hline $\mathrm{B}$ & 1 & -1 & -0.3 to -0.6 \\
\hline & $\begin{array}{l}\text { Existing summa- } \\
\text { tion law }\end{array}$ & \multicolumn{2}{|l}{ Modified summation law } \\
\hline
\end{tabular}

Table VI shows the resultant VUFs at the POE of a 12.47 $\mathrm{kV}$ radial network supplying a randomly varying, three-phase, 10 MVA constant power type (normally distributed) load [2] which are obtained using deterministic formulation (1) and statistical approaches (using existing and revised general summation law $\left(V U F_{P O E \text {,stat }}=\left(\left|V U F_{P O E}^{\text {load }}\right|^{\alpha}-\left|V U F_{P O E}^{\text {line }}\right|^{\alpha}\right)^{\frac{1}{\alpha}}\right.$ as the $\left.K_{i}=-1\right)$ ).
TABLE VI

RESUlTANT VUF AT THE POE: 95\% PROBABILISTIC VALUES

\begin{tabular}{|c|c|c|c|}
\hline \multirow{2}{*}{$\begin{array}{l}\text { line } \\
\text { length } \\
\mathrm{km}\end{array}$} & \multirow{2}{*}{$\begin{array}{l}\text { Deterministic } \\
\text { approach } \\
\left|V U F_{P O E}\right| \\
95 \% \text { value }\end{array}$} & \multicolumn{2}{|c|}{$V U F_{P O E}$, stat $95 \%$ value } \\
\hline & & $\begin{array}{l}\text { Revised summa- } \\
\text { tion law }\end{array}$ & $\begin{array}{l}\text { Existing sum- } \\
\text { mation law }\end{array}$ \\
\hline 1 & 0.34 & 0.30 & 0.52 \\
\hline 2 & 0.74 & 0.70 & 1.15 \\
\hline 3 & 1.31 & 1.32 & 1.94 \\
\hline 4 & 2.04 & 2.12 & 2.95 \\
\hline 5 & 3.14 & 3.35 & 4.34 \\
\hline
\end{tabular}

\section{CONCLUSIONS}

The paper has summarised the recent studies completed in relation to VU management. The generalised outcomes and findings of compliance assessment techniques covering both radial and interconnected networks are used to enhance the understanding of some of the key aspects discussed in the IEC VU emission allocation methodology and hence further improvements are suggested. Accordingly, VU propagation, $\mathrm{k}_{\mathrm{uE}}$ factor approach and the application of a summation law for aggregation of randomly varying unbalance have been reviewed and revised by identifying the dependencies of these factors/approaches on various system parameters. Based on the work completed, avenues for further research on the subject of VU management are expected to open to improve the usability of the proposed methodologies under practical considerations. In particular, real time system data analysis using state estimation based techniques can be adopted to account for the diverse behaviour of the power system. Similar to the $\mathrm{k}_{\mathrm{uE}}$ factor approach in sharing $\mathrm{VU}$, a new concept can be developed to quantify the enhancement of total VU emission absorption capacity of the system by the connection of threephase induction motors which can be useful in developing power quality market aspects to reward induction motor loads for helping to correct pre-existing VU levels. Further, a new index may be developed to quantify the responsibilities of different stakeholders for the initiation and propagation of VU in largely interconnected networks.

\section{REFERENCES}

[1] "Electromagnetic compatibility (EMC) - limits - assessment of emission limits for the connection of unbalanced installations to MV, HV and EHV power systems", Technical Report IEC/TR 61000-3-13, Ed. 1, International Electrotechnical Commission, 2008

[2] U. Jayatunga, "Further Contributions to the Development of the Technical Report IEC/TR 61000-3-13:2008 on Voltage Unbalance Management Methodologies", Ph.D. Dissertation, School of Electrical, Computer and Telecommunications Engineering, University of Wollongong, Australia, 2013, available at http://ro.uow.edu.au/theses/3998/.

[3] "Review of disturbance emission assessment techniques", CIGRE/CIRED C4.109 WG Report 468, June 2011.

[4] U. Jayatunga, S. Perera and P. Ciufo, "Voltage unbalance emission assessment in radial power systems", IEEE Transactions on Power Delivery, vol.27, no.3, pp.1653-1661, July 2012.

[5] U. Jayatunga, S. Perera, P. Ciufo, and A. P. Agalgaonkar, "Voltage Unbalance Emission Assessment in Interconnected Power Systems", IEEE Transactions on Power Delivery, vol.28, no.4, pp.2383-2393, Oct. 2013.

[6] U. Jayatunga, S. Perera, P. Ciufo, and A. P. Agalgaonkar, "Voltage Unbalance Emission Assessment: Sources of Contribution and their Ranking", Australasian Universities Power Engineering Conference, AUPEC 2013, Hobart, Tasmania, Australia, 29 Sept.- Oct. 2013.

[7] U. Jayatunga, S. Perera, P. Ciufo, and A. P. Agalgaonkar, "Deterministic Methodologies for the Quantification of Voltage Unbalance Propagation in Radial and Interconnected Networks", IEEE Transactions on Power Delivery, under review, available at http://works.bepress.com/pciufo/33.

[8] U. Jayatunga, S. Perera and P. Ciufo, "VU management in power systems based on IEC 61000-3-13:2008: implications on the use of ' $k_{u E}$ factor"', 2012 IEEE 15th International Conference on Harmonics and Quality of Power (ICHQP), pp.936,942, 17-20 June 2012. 
[9] P. Paranavithana, "Contributions Towards the Development of the Technical Report IEC/TR 61000-3-13 on VU Emission Allocation", Ph.D. Dissertation, School of Electrical, Computer and Telecommunications Engineering, University of Wollongong, Australia, March 2009.

[10] H. Renner, "Voltage unbalance emission assessment", Electric Power Quality and Supply Reliability Conference, vol.16, no.18, pp.43-48, June 2010 . 